ICRC by means of a number of publications, in particular the school textbook which was distributed to schoolchildren in a great many countries.

The League of Red Cross Societies submitted a report entitled Solidarity in Case of Disaster, in which Mr. J.-P. Robert-Tissot stressed the importance of agreements on mutual assistance, a concept which has developed considerably in Red Cross circles in recent years.

\title{
REAPPRAISAL OF THE ROLE OF THE RED CROSS
}

It will be recalled that the Standing Committee of the International Red Cross, at its meeting in Cannes on 22 April 1970, considered certain aspects of a " reappraisal of the role of the International Red Cross in the light of present-day conditions" and that it requested the ICRC and the League to undertake a joint study of those problems.

Complying with that request, the International Committee of the Red Cross and the League of Red Cross Societies announced the formation of a Joint Committee for the Reappraisal of the Role of the Red Cross. At the same time, Mr. Donald Tansley (Canada) was appointed Director of the " Reappraisal" which will be a profound study of the present and future role of the Red Cross throughout the world.

Mr. Tansley, who is presently Executive Vice-President of the Canadian International Development Agency (CIDA), will assume his new functions on 1 February 1973, in Geneva.

The purpose of the "Reappraisal "-which is expected to take from two to three years-is to collect meaningful data and relevant information leading to objective conclusions concerning Red Cross policy and organization, necessary to meet challenges which confront the Red Cross today and which are likely to develop in coming decades. 